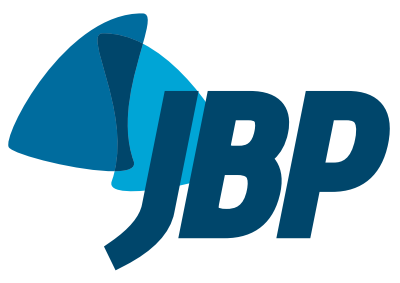

\title{
Exploratory analysis of requests for authorization to dispense high-cost medication to COPD patients: the São Paulo "protocol"
}

\author{
Regina Maria Carvalho-Pinto1,a, Ingredy Tavares da Silva, ${ }^{1,2, b}$, \\ Lucas Yoshio Kido Navacchia, , , Flavia Munhos Granja ${ }^{1,2, \mathrm{~d}}$, \\ Gustavo Garcia Marques 1,2,e, Telma de Cassia dos Santos Nery ${ }^{1, f}$, \\ Frederico Leon Arrabal Fernandes ${ }^{1, \mathrm{~g}}$, Alberto Cukier ${ }^{1, \mathrm{~h}}$, Rafael Stelmach ${ }^{1, \mathrm{i}}$
}

1. Divisão de Pneumologia, Instituto do Coração - InCor - Hospital das Clínicas, Faculdade de Medicina, Universidade de São Paulo, São Paulo (SP) Brasil.

2. Disciplina de Saúde Coletiva, Faculdade de Medicina, Centro Universitário São Camilo, São Paulo (SP) Brasil.

a. (ID) http://orcid.org/0000-0002-6344-2127

b. (D) http://orcid.org/0000-0003-1596-5190

c. (D) http://orcid.org/0000-0003-4964-1792

d. (iD) http://orcid.org/0000-0002-2516-5480

e. (iD http://orcid.org/0000-0002-7170-7818

f. (D) http://orcid.org/0000-0003-3085-5977

g. (D) http://orcid.org/0000-0002-3057-5716

h. (D) http://orcid.org/0000-0002-7217-9498

i. (D) http://orcid.org/0000-0002-5132-1934

Submitted: 12 November 2018

Accepted: 29 April 2019.

Study carried out in the Divisão de Pneumologia, Instituto do Coração, Hospital das Clínicas, Faculdade de Medicina, Universidade de São Paulo, São Paulo (SP) Brasil.

\begin{abstract}
Objective: A resolution passed by the government of the Brazilian state of São Paulo established a protocol for requesting free COPD medications, including tiotropium bromide, creating regional authorization centers to evaluate and approve such requests, given the high cost of those medications. Our objective was to analyze the requests received by an authorization center that serves cities in the greater metropolitan area of (the city of) São Paulo between 2011 and 2016. Methods: Data regarding the authorization, return, or rejection of the requests were compiled and analyzed in order to explain those outcomes. Subsequently, the clinical and functional data related to the patients were evaluated. Results: A total of 7,762 requests for dispensing COPD medication were analyzed. Requests related to male patients predominated. Among the corresponding patients, the mean age was 66 years, $12 \%$ were smokers, $88 \%$ had frequent exacerbations, and $84 \%$ had severe/very severe dyspnea. The mean FEV was $37.2 \%$ of the predicted value. The total number of requests decreased by $24.5 \%$ from 2012 to 2013 and was lowest in 2015. Most (65\%) of the requests were accepted. The main reasons for the rejection/return of a request were a post-bronchodilator $\mathrm{FEV}_{1}$ / FVC ratio $>0.7$, a post-bronchodilator $\mathrm{FEV}_{1}>50 \%$ of the predicted value, and failure to provide information regarding previous use of a long-acting $\beta_{2}$ agonist. During the study period, the total number of requests returned/rejected decreased slightly, and there was improvement in the quality of the data included on the forms. Conclusions: Here, we have identified the characteristics of the requests for COPD medications and of the corresponding patients per region served by the authorization center analyzed, thus contributing to the improvement of local public health care measures.
\end{abstract}

Keywords: Pulmonary disease, chronic obstructive; Clinical protocols; Drug costs; Tiotropium bromide.

\section{INTRODUCTION}

Worldwide, COPD is responsible for the high use of health care resources due to the high rates of morbidity and mortality of the disease. ${ }^{(1)}$ It is the fourth leading cause of death in the world, ${ }^{(2)}$ and it is estimated that there are 7 million individuals with COPD in Brazil. ${ }^{(1.3)}$ According to data from the Departamento de Informática do Sistema Único de Saúde (SUS, Unified Health System), annual expenditures related to hospitalizations due to COPD in Brazil have remained above $\mathrm{R} \$ 100$ million every year since 2011 . In 2017 , there were 119,000 COPD-related hospitalizations, with a total expenditure of $\mathrm{R} \$ 108$ million. ${ }^{(4)}$

Given COPD evolution and prognosis, the focus of its treatment is to reduce symptoms and slow down the progression of the disease, improving dyspnea, exercise tolerance, and quality of life. In addition, exacerbations should be prevented and treated, reducing the number of hospitalizations. ${ }^{(2,5,6)}$

Non-pharmacological and pharmacological treatment is established in accordance with national and international guidelines, ${ }^{(2,7)}$ the pillars of treatment being the use of long-acting bronchodilators. The evolution in the knowledge of the disease and in clinical research resulted in the introduction of new drugs for the treatment of COPD. However, the unrestricted incorporation of new treatments represents a high cost to SUS, especially regarding high-prevalence diseases.

The São Paulo State Department of Health, by means of Resolution no. 278 of July 26, 2007,(8) introduced a protocol for the free treatment of patients with COPD for the first time in Brazil. The protocol innovatively established free hierarchical treatment for all severity levels of the disease, including the rational use of long-acting $\beta_{2}$

Correspondence to:

Rafael Stelmach. Divisão de Pneumologia, Avenida Enéas de Carvalho Aguiar, 44, $5^{\circ}$ andar, Cerqueira Cesar, CEP 05403-000, São Paulo, SP, Brasil.

Tel.: 5511 2661-5695. E-mail: rafael.stelmach@incor.usp.br

Financial support: This study received financial support from the Grupo de Obstrução da Divisão de Pneumologia, Instituto do Coração, Hospital das Clínicas,

Faculdade de Medicina da Universidade de São Paulo. 
agonists (LABA) and long-acting muscarinic antagonists (LAMA), allowing access to treatment of a greater number of patients by SUS. In addition, São Paulo pioneered the introduction of tiotropium bromide into the therapeutic arsenal for the treatment of COPD in Brazil. Resolution no. $278^{(8)}$ also included a set of criteria and documents necessary for the request of COPD medications, creating 13 authorization centers (universities or hospitals of the state network), indicated by the Sociedade Paulista de Pneumologia e Tisiologia (São Paulo Thoracic Association), which cover practically all the regional health care divisions in the state. The processes/completion of request forms initiate in the Farmácias de Medicamentos Especializados (Specialized Drug Pharmacies) in the referral areas and are sent to the authorization centers. One of those centers is located in the Instituto do Coração of the Hospital das Clínicas, Faculdade de Medicina da Universidade de São Paulo (InCor-HC-FMUSP), located in the city of São Paulo, which serves 38 municipalities grouped into five regions (Chart 1 ), with a resident population of more than 8 million people. To our knowledge, this center serves the greatest number of patients.

According to one study, ${ }^{(1)}$ the mean prevalence of COPD is $16 \%$ in the population over 45 years of age, and $70 \%$ of that population have yet to be diagnosed with the disease and, therefore, have received no treatment. Thus, we can infer that the set of those 38 municipalities had an approximate population of over half a million untreated adults in 2015. According to data from the Departamento de Informática do SUS, ${ }^{(4)}$ in that set of municipalities, the mortality rate due to COPD per 100,000 population showed a trend toward an increase between 2011 and 2015.

As of 2015, with the publication of the technical note of the Grupo de Assistência Farmacêutica da Coordenadoria de Ciência, Tecnologia e Insumos Estratégicos de Saúde (GAF/CCTIES, Pharmaceutical Assistance Group of the Coordination of Science, Technology, and Strategic Health Supplies) no. 02 of January $15,2015{ }^{(9)}$ the flow for COPD drug dispensing was standardized, including a medical report called "Annex B: Tiotropium Request Medical Report" that included clinical and functional data of the patients.
This guideline is used throughout the state of São Paulo and involves the 13 authorization centers.

The objective of the present study was to analyze the characteristics of tiotropium bromide requests for the treatment of COPD received between 2011 and 2016, based on data from the decisions of expert physicians of the InCor-HC-FMUSP authorization center. Reasons for the return or refusal of medication requests were assessed in an attempt to identify the major difficulties in complying with the protocol. The secondary objective was to determine the clinical and functional profile of the COPD patients by means of the data available on specific tiotropium bromide requests and medical reports received between 2015 and 2016.

\section{METHODS}

As of 2011, the InCor-HC-FMUSP authorization center systematized the collection of data regarding the evaluation reports on the medication requests, compiling the reasons for the decision making (approval, return, or rejection) in a spreadsheet. After the publication of the technical note GAF/CCTIES no. 02 ${ }^{(9)}$ and the adoption of Annex B, which contains clinical and functional data of the patients, those data were also compiled in the database.

The following variables were collected: evaluation report results; reasons for returns or rejections (insufficient or erroneous data); age; International Classification of Diseases (10th edition) $\operatorname{code}^{(10)}$; disease duration; smoking history; influenza and/or pneumococcal vaccination; previous pharmacological treatment; clinical assessment of dyspnea (modified Medical Research Council scale); exacerbations; and lung function data.

A descriptive analysis of the collected data was carried out, evaluating the number of requests per region over time. The reasons for approval and the temporal evolution of this decision were evaluated. As of 2015, the clinical and functional profile of those patients was determined, based on the reports (Annex B). The descriptive statistical analysis was performed using Excel 2013, Sigma Stat, version 3 (Systat Software,

Chart 1. Farmácias de Medicamentos Especializados (Specialized Drug Pharmacies) by region and coverage of municipalities served by the authorization center in the Instituto do Coração do Hospital das Clínicas da Faculdade de Medicina da Universidade de São Paulo.

\begin{tabular}{|c|c|c|}
\hline Region & Municipalities & $\begin{array}{l}\text { Total population/ } \\
\text { region, } 2016\end{array}$ \\
\hline FRANCO DA ROCHA & Caieiras, Cajamar, Francisco Morato, Franco da Rocha, Mairiporã & 581,464 \\
\hline MOGI DAS CRUZES & $\begin{array}{l}\text { Arujá, Biritiba-Mirim, Ferraz de Vasconcelos, Guararema, } \\
\text { Itaquaquecetuba, Mogi das Cruzes, Poá, Salesópolis, Santa Isabel, } \\
\text { Suzano }\end{array}$ & $1,593,224$ \\
\hline GUARULHOS & Guarulhos & $1,337,087$ \\
\hline $\begin{array}{l}\text { SANTO ANDRÉ } \\
\text { (ABC-Hospital Estadual } \\
\text { Mário Covas) }\end{array}$ & $\begin{array}{l}\text { Diadema, Mauá, Ribeirão Pires, Rio Grande da Serra, Santo André, } \\
\text { São Bernardo do Campo, São Caetano do Sul }\end{array}$ & $2,736,683$ \\
\hline OSASCO & $\begin{array}{l}\text { Barueri, Carapicuíba, Cotia, Embu, Embu-Guaçu, Itapecerica da } \\
\text { Serra, Itapevi, Jandira, Juquitiba, Osasco, Pirapora do Bom Jesus, } \\
\text { Santana do Parnaíba, São Lourenço da Serra, Taboão da Serra }\end{array}$ & $2,906,759$ \\
\hline
\end{tabular}


Inc., San José, CA, USA), and DMSS, version 18 (DMSS Software, São Paulo, Brazil). The project was approved by the research ethics committee of the institution (CAAE no. 67319817.5.0000.006).

\section{RESULTS}

Between 2011 and 2016, 7,762 request forms were analyzed-an annual average of 1,293 requests. The total number of requests per year/region is described in Figure 1. Most requests were issued in the $A B C$ and Osasco regions $-3,085$ and 2,429 requests, respectively-being responsible for $71 \%$ of the requests. Taking into account all municipalities, the total number of requests decreased by $24.5 \%$ from 2012 to 2013 and was lowest in 2015 . The mean number of requests per 100,000 population/year per region can be seen in Figure 2.

Although most of the requests were authorized between 2011 and 2016, 35\% were initially returned or rejected because of the reasons described in Chart 2 . The total number of returned or rejected requests showed a slight reduction during the study period (from $38 \%$ in 2011 to $35 \%$ in 2016). Rejection or return of the requests was often due to more than one reason. However, the most common reasons were as follows: a post-bronchodilator $\mathrm{FEV}_{1} / \mathrm{FVC}$ ratio $>0.7$; a post-bronchodilator $\mathrm{FEV}_{1}>50 \%$ of the predicted value; and failure to provide information regarding previous treatment with a LABA, as defined in the Resolution.

Over time, there was an improvement in the completion of the forms, mainly represented by a decrease in the requests with no spirometry results, lack of prescription, inadequate dosing schedule, or failure to provide information regarding the previous treatment with a LABA. The latter reason was responsible for 135 and 56 returned requests in 2011 and 2016, respectively. The year 2015 was critical in relation to the absence or incompleteness of a specific medical

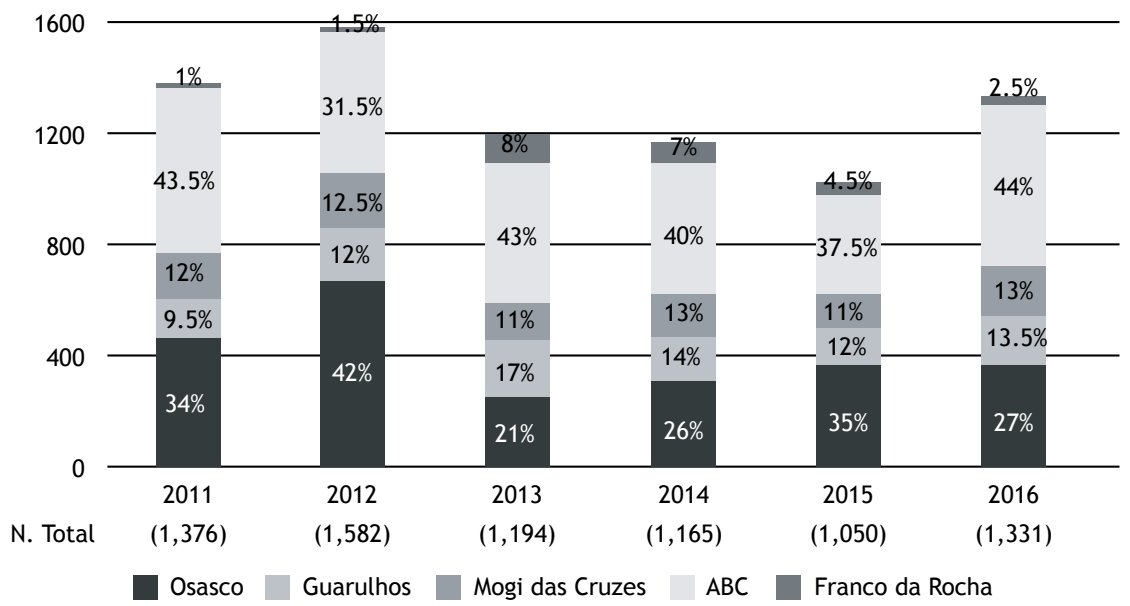

Figure 1. Total annual requests received by the authorization center in the Instituto do Coração do Hospital das Clínicas da Faculdade de Medicina da Universidade de São Paulo by region, 2011-2016 (N = 7,762).

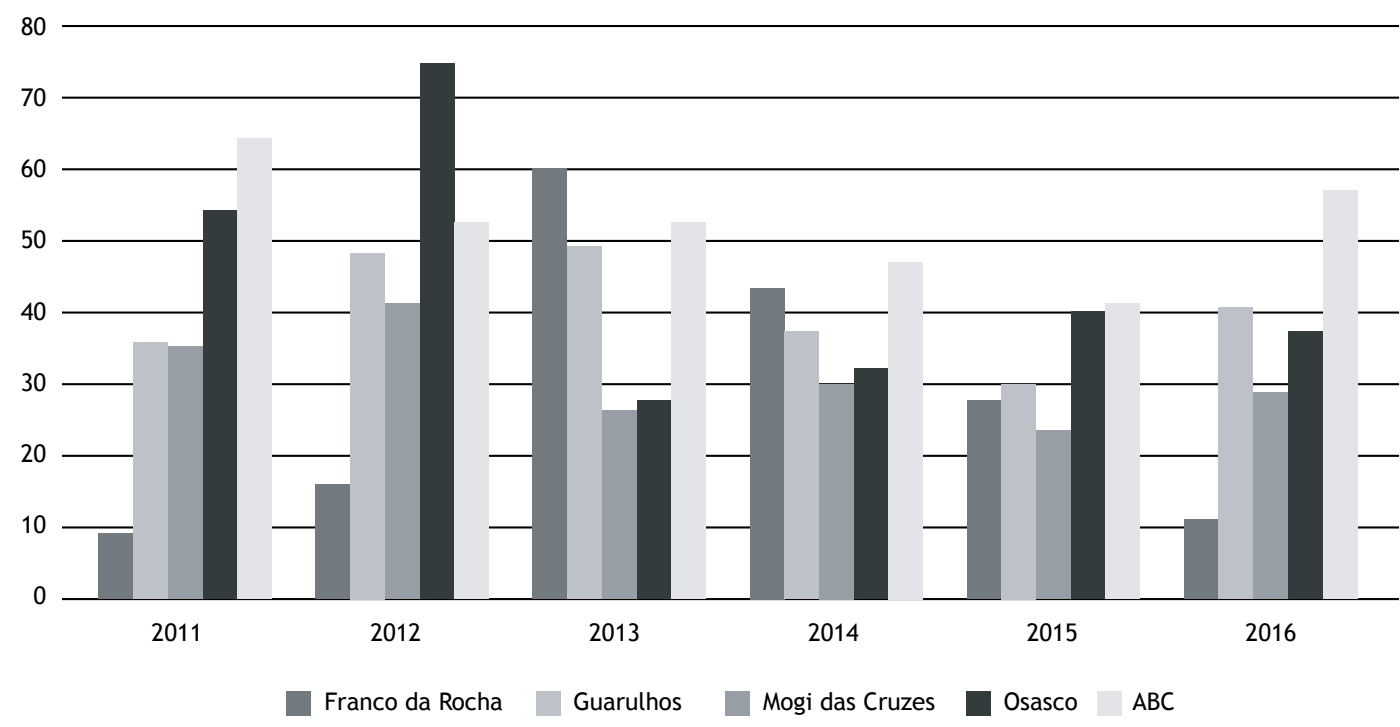

Figure 2. Annual rate of requests received by the authorization center in the Instituto do Coração do Hospital das Clínicas da Faculdade de Medicina da Universidade de São Paulo by region per 100,000 population, 2011-2016 $(\mathrm{N}=7,762)$. 
report enclosed in the tiotropium bromide request. It should be noted that the proportion of returns/ rejections due to an $\mathrm{FEV}_{1} / \mathrm{FVC}$ ratio $>0.7$ remained similar during the study period. The proportion of reasons for returns/rejections per year between 2011 and 2016 can be seen in Figure 3.

The profile of patients whose requests were authorized ( $n=2,317$ ) between 2015 and 2016 is shown in Table 1. Requests related to male patients predominated. Among the corresponding patients, the mean age was 66 years. The most common code of the International Classification of Diseases (10th version) was $\mathrm{J44}$ ( $96 \%$ of all requests). The data showed that $12 \%$ of the patients were smokers at the time of the request. According to the medical reports, only $15 \%$ received drug therapy for smoking cessation, and the mean time since smoking cessation was $10.0 \pm 9.4$ years. In addition, the reports revealed a high prevalence of patients that had exacerbations, $88 \%$ being diagnosed with frequent exacerbations (two or more exacerbations in the last year). The analysis of dyspnea severity showed very symptomatic patients-modified Medical Research Council scores $\geq 3$ in $84 \%$ of the patients. The mean $\mathrm{FEV}_{1}$ was $37.2 \%$ of the predicted

Chart 2. Reasons for returning/rejecting tiotropium bromide requests by the authorization center in the Instituto do Coração do Hospital das Clínicas da Faculdade de Medicina da Universidade de São Paulo, 2011-2016.

\section{Reason}

1. Lack of spirometry results

2. Post-bronchodilator $\mathrm{FEV}_{1}>50 \%$ of the predicted value

3. Post-bronchodilator $\operatorname{VEF}_{1} / \mathrm{CVF}>0.7$

4. Lack of or incomplete medical report

5. No information on previous use of a long-acting $B_{2}$ agonist

6. Lack of or inadequate dosage prescription value, demonstrating severe functional limitation in the patients whose requests were accepted (Table 1).

\section{DISCUSSION}

The present study shows the analysis of data available in the medication requests for COPD treatment in the public health care system of the state of São Paulo received by the InCor-HC-FMUSP authorization center between 2011 and 2016. It was possible to analyze the reasons for returns or rejections of the requests, the most common ones being failure to provide information regarding spirometry or post-bronchodilator $\mathrm{FEV}_{1}>$ $50 \%$ of the predicted value.

Resolution no. $278,{ }^{(8)}$ modified over time, was based on a protocol comprising inclusion criteria and a flow chart indicating the prescription of each group of medications that had been previously selected in a SUS referral center for the treatment of COPD patients. ${ }^{(11)}$ The protocol used the recommendations of the best evidence available at the time, indicating the need to introduce new medications, such as tiotropium bromide, in order to preserve treatment efficacy according to the severity of COPD. In 2007, the state of São Paulo was a pioneer in the implementation of that protocol, which already recommended the use of a long-acting bronchodilator plus a short-acting bronchodilator in patients with COPD who remained symptomatic and emphasized that the treatment should be adapted to local conditions, considering the resources available and the clinical characteristics of the patients.

The importance of tiotropium bromide in the treatment of COPD has also been demonstrated in various randomized trials and in a real-life study. ${ }^{(6)}$ The combination of tiotropium bromide, which is a bronchodilator classified as a LAMA, is beneficial in patients with severe and very severe COPD. The use of

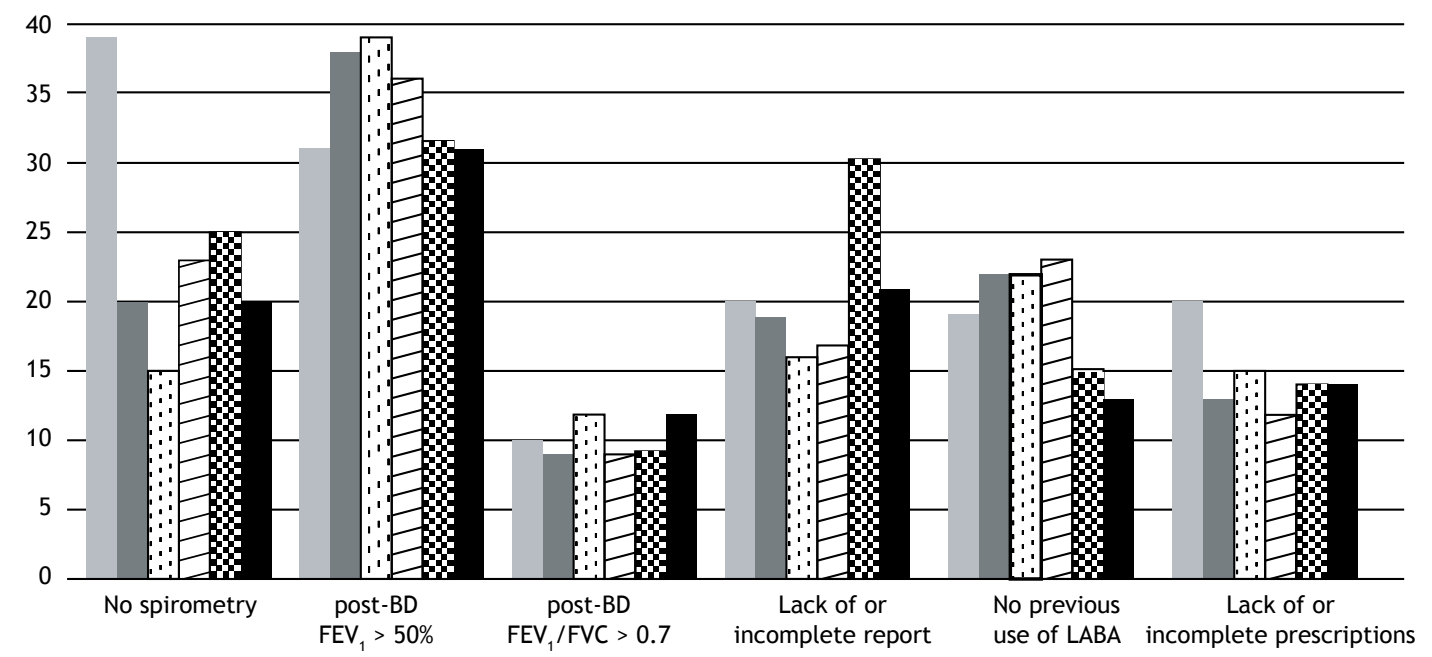

2011

Figure 3. Annual proportion of returns/rejections of requests received by the authorization center in the Instituto do Coração do Hospital das Clínicas da Faculdade de Medicina da Universidade de São Paulo according to the main outcomes, 2011-2016 ( $N=2,718)$. post-BD: after the use of bronchodilator; and LABA: long-acting $\beta_{2}$ agonists. 
Table 1. Characteristics of the patients whose requests for the dispensing of tiotropium bromide were accepted by the authorization center in the Instituto do Coração do Hospital das Clínicas da Faculdade de Medicina da Universidade de São Paulo. 2011-2016. ${ }^{\mathrm{a}}$

\begin{tabular}{lc}
\multicolumn{1}{c}{ Characteristic } & Result \\
Male gender, \% & 52 \\
Age, years & $66.0 \pm 10.6$ \\
Disease duration & $9.5 \pm 7.4$ \\
Smoker & $171(12)$ \\
Former smoker & $1,259(87)$ \\
Smoking history, pack-years & $42 \pm 12$ \\
Influenza vaccination, \% & 84 \\
Pneumococcal vaccination, \% & 16 \\
Exacerbation in the last year, \% & 94 \\
$\geq 2$ exacerbations in the last year, \% & 88 \\
mMRC scale score, \% & \\
$\quad 1$ & 3 \\
2 & 13 \\
3 & 52 \\
$\quad 4$ & 32 \\
FEV $_{1}$, L & $1.0 \pm 0.9$ \\
FEV $_{1}, \%$ predicted & $37.2 \pm 2.0$ \\
\hline
\end{tabular}

mMRC: modified Medical Research Council.

avalues expressed as $\mathrm{n}(\%)$ or as mean $\pm \mathrm{SD}$, except where otherwise indicated.

a LAMA alone as an initial treatment or its association with a LABA is indicated in patients with COPD and moderate obstructive lung disease. ${ }^{(7)}$

After the state of São Paulo, Espírito Santo (2009), ${ }^{(12)}$ Minas Gerais (2010), ${ }^{(13)}$ Ceará $(2010),{ }^{(14)}$ the Federal District (2012),(15) and Pernambuco (2013) ${ }^{(16)}$ also implemented the dispensing of tiotropium bromide, using specific protocols. The protocol of the state of São Paulo was used as a reference, incorporating the specificities of each region.

In 2013, a study in Canada analyzed the impact of implementing public drug dispensing policies for COPD patients in British Columbia between 2007 and 2009. (17) Initially, there was an increase in total costs; however, there was a reduction in the costs paid by the patient himself/herself and his/her private insurance companies: a 19\% drop (\$2.97 million Canadian dollars) in total spending on medications. ${ }^{(17)}$

In the elaboration of the São Paulo protocol that gave rise to Resolution no. $278,{ }^{(8)}$ an additional cost of $\mathrm{R} \$$ 400 million/year was estimated due to the dispensing of tiotropium bromide. The costs were estimated based on the prevalence of severe patients, ${ }^{(1)}$ resulting in discussions regarding the financial impact of the free dispensing of that medication and strengthening the debate for the inclusion of technical analyses of the requests, which made the implementation of the protocol viable. The use of rational dispensing based on well-defined criteria and authorization centers has reduced the costs to approximately one quarter of the predicted value. Considering the characteristics of the population and the access to medications, it is relevant that the protocol and the resolution of the state of São Paulo guaranteed access of the population with severe/ very severe COPD to the medication.

The variations in the rates of requests per 100,000 population in the different regions can be due to various factors. However, we have no information on the regional characteristics regarding health care services and access to the exams in those regions, although the mapping of future public health care actions is of great value, even to analyze the impact of such factors on treatment protocols.

The implementation of protocols with well-established criteria for dispensing medications can significantly contribute with data to public health care managers and rationalize access to treatment. Here, the administrative flow of requests, authorization center evaluations, and outcomes (approval, return, or rejection) refers only to the dispensing of tiotropium bromide. The other medications provided for in the protocol are authorized locally, with no need for the systematic control of their use.

In 2015, the technical note GAF/CCTIES no. $2^{(9)}$ addressed the need for document standardization for dispensing medications, including the standardized medical report for tiotropium bromide requests. That model has met the needs for verification, in a structured way, regarding the criteria ${ }^{(9)}$ defined in the protocol. The elaboration of a database containing such information allowed the characterization of the population involved in that protocol. It is important to note that, although prior knowledge of medication dispensing rules might create a bias in completing the request form, $35 \%$ of those were initially returned or rejected due to noncompliance with protocol criteria, signaling the need for a specific audit.

Our data revealed that the mean age of the patients was 66 years, and most were males, ex-smokers, and very symptomatic. In addition, there was a high prevalence of influenza vaccination, exacerbations, and severe functional impairment.

The data in the medical reports indicated that more than $80 \%$ of the patients received influenza vaccine; however, only $16 \%$ received pneumococcal vaccine. This information was collected from data filled out by physicians retrospectively and, probably, based on patient self-report. The use of influenza and pneumococcal vaccination in the elderly with chronic lung disease showed significant reductions in the risk of hospitalization due to pneumonia and of death, respectively (from $52 \%$ to $72 \%$ and from $70 \%$ to $82 \%) .{ }^{(18)}$ This shows the need to disclose the benefits of pneumococcal vaccination to COPD patients and to the health professionals who serve them.

Patients with COPD usually have one or two exacerbations per year, especially during winter. ${ }^{(18)}$ In the present study, $88 \%$ of the patients had two or more exacerbations/year. Although this information was probably collected from patient self-reports, it might indicate that this group of patients require frequent 
medical care. We highlight that a Brazilian study published in $2017^{(19)}$ pointed to important indicators in COPD patients with exacerbations: in-hospital mortality during exacerbation, $3.6 \%-11.0 \%$; risk of hospitalization in the year following hospitalization, 23-43\%; and calculated fatality (excess mortality compared with stable COPD), $15.6 \%$. This highlights the importance of measures to prevent and treat COPD exacerbations.

Due to the high cost of tiotropium bromide compared with that of LABA or LABA + inhaled corticosteroid, the protocol stipulated that tiotropium should be used as a second-line medication. Thus, in the present study, all of the requests accepted indicated the prior use of LABA, a criterion to be met for tiotropium bromide dispensing. The failure to inform that as an initial reason for rejection was $19 \%$ and $13 \%$ in 2011 and 2016, respectively, which may signal an increasing learning curve of the physicians in relation to the protocol criteria.

Spirometry is an essential test for the definitive diagnosis of COPD, ${ }^{(2)}$ and $\mathrm{FEV}_{1}$ is one of the criteria for the approval of tiotropium bromide requests. In the present study, the lack of spirometry results in the requests as a reason for their return/rejection fell from $39 \%$ in 2011 to $19 \%$ in 2016 . This fact might indicate a better knowledge of the protocol criteria during time, or eventually, that there was greater access to spirometry. This is relevant since the underuse of spirometry has been reported to be a determining factor in the underdiagnosis of COPD. ${ }^{(5)}$ Underuse of spirometry was also identified in a Latin-American study ${ }^{(1)}$ in which only $20 \%$ of the patients with COPD had performed previous spirometry. This is probably due to the lack of resources for equipment availability, lack of patient access to the test, or even lack of knowledge on the part of health professionals. It is also worth mentioning that approximately $10 \%$ of the requests were returned/rejected each year due to spirometry results that showed no obstructive disorder. At the moment, we have no access to information in order to verify unbiasedly whether the origin of those requests came from professionals specializing in pulmonology or not.
It is impossible to know the subsequent follow-up of the patients who received the medications by the analysis of the request forms. Renewals are dispensed directly by the requesting site; therefore, the authorization center has no information regarding the universe of patients who benefited from the treatment and those whose response was inadequate; for the latter, we should consider the possibility of discontinuation of the medication and search for therapeutic alternatives.

To our knowledge, this is the first study that presents data regarding medication requests related to Resolution no. $278,{ }^{(8)}$ and some limiting factors must be taken into account. The analysis is based on retrospectively completed data included on the tiotropium bromide requests. The authorization center has no control over how this information is collected, and prior knowledge of the medication dispensing criteria could eventually create a bias in the completion of the reports. We also have no information related to factors such as availability of professionals for patient health care, physician knowledge about the protocol, access to spirometry, among others.

Implementing and meeting protocol criteria for dispensing medications is an important guide in the clinical practice. The essential action for the promotion of health, as recommended by the World Health Organization, (20) indicate that the rational use of medications is one of the most important components of the policies promoted by the Organization.

In summary, the analysis of the data allowed us to identify the characteristics of the requests for tiotropium bromide and of the corresponding patients per region served by InCor-HC-FMUSP authorization center (38 municipalities) between 2011 and 2016, which can contribute to the optimization of specific and local public health care measures. Data from authorization centers are living records of COPD morbidity in the country, and the publication of those data might prompt reflection to authorization centers in the state of São Paulo and in other states and stimulate the publication of data collected in those centers.

\section{REFERENCES}

Menezes AM, Perez-Padilla R, Jardim JR, Muiño A, Lopez MV Valdivia G, et al. Chronic obstructive pulmonary disease in five Latin American cities (the PLATINO study): a prevalence study. Lancet. 2005;366(9500):1875-81. https://doi.org/10.1016/S01406736(05)67632-5

2. Global Initiative for Chronic Obstructive Lung Disease - GOLD [homepage on the Internet]. Bethesda: Global Initiative for Chronic Obstructive Lung Disease [cited 2018 Jan 20]. Global Strategy for the Diagnosis, Management, and Prevention of COPD 2017. Available from: http://www.goldcopd.org/

3. Giacomelli IL, Steidle LJ, Moreira FF, Meyer IV, Souza RG, Pincell MP. Hospitalized patients with COPD: analysis of prior treatment J Bras Pneumol. 2014;40(3):229-37. https://doi.org/10.1590/S180637132014000300005

4. Brasil. Departamento de Informática do SUS - DATASUS [homepage on the Internet]. Brasília: Ministério da Saúde [cited 2018 Oct 1]. Available from: http://datasus.saude.gov.br/

5. Rabahi MF. Epidemiologia da DPOC: enfrentando desafios. Pulmão RJ. 2013;22(2):4-8.
6. Fernandes FL, Pavezi VA, Dias SA Jr, Carvalho-Pinto RM, Stelmach $R$, Cukier A. Short-term effect of tiotropium in COPD patients being treated with a beta2 agonist [Article in Portuguese]. J Bras Pneumol. 2010;36(2):181-9. https://doi.org/10.1590/S180637132010000200005

7. Sociedade Brasileira de Pneumologia e Tisiologia. II Consenso Brasileiro sobre Doença Pulmonar Obstrutiva Crônica - DPOC - 2004 J Bras Pneumol. 2004;30(Suppl 5):S1-S42.

8. São Paulo. Secretaria de Estado da Saúde. Resolução n 278 de 26 de julho de 2007. Diário Oficial do Estado. 2007 Jul 27; Seção I. p. 27-9.

9. São Paulo. Secretaria de Estado da Saúde [homepage on the Internet]. São Paulo: a Secretaria; [cited 2018 Jul 18]. Nota técnica GAF/CCTIES n 02 de 15 de janeiro de 2015. [Adobe Acrobat document, 7p.]. Available from: http://www.saude.sp.gov.br/ resources/ses/perfil/gestor/assistencia-farmaceutica/notas-tecnicas/ nota_tecnica_02_assist_farm_2015.pdf

10. Organização Mundial da Saúde. Classificação Estatística Internacional de Doenças e Problemas Relacionados à Saúde, $10^{\text {a }}$ versão-CID-10 [cited 2018 Jan 15]. Busca de CID10 por código J44. Available from: 
https://www.cid10.com.br/buscacode?query=j44

11. Universidade de São Paulo. Hospital das Clínicas. Divisão de Farmácia. Disciplina de Pneumologia. Grupo de Doenças Obstrutivas. Protocolo Clínico e Diretrizes Terapêuticas-Doença Pulmonar Obstrutiva Crônica. 2007 Mar 25.

12. Espírito Santo. Secretaria de Estado da Saúde [homepage on the Internet]. Vitória: Gerência Estadual de Assistência Farmacêutica/a Secretaria [cited 2018 Jul 19]. Portaria 053-R. 2009 May 12. Available from: http://ioes.dio.es.gov.br/portal/visualizacoes/jornal/2041/\#/ p:23/e:2041

13. Ceará. Secretaria da Saúde do Estado [homepage on the Internet] Fortaleza: a Secretaria; [cited 2018 Apr 26]. Protocolo de atendimento a pacientes portadores de Doença Pulmonar Obstrutiva Crônica (DPOC) no Estado do Ceará. [Adobe Acrobat document, 36p.]. Available from: https://www.saude.ce.gov.br/wp-content/uploads/ sites/9/2018/06/protocolo_doenca_pulmonar_obstrutiva_cronica.pdt

14. Distrito Federal. Secretaria de Estado de Saúde. Brasília: a Secretaria; [cited 2018 Jul 17]. Protocolo Clínico e Diretrizes Terapêuticas: Doença Pulmonar Obstrutiva Crônica; 2012.

15. Minas Gerais. Secretaria de Estado de Saúde [homepage on the Internet]. Belo Horizonte: a Secretaria; [cited 2018 Jul 17]. Resolução $n^{\circ} 3203$ de 03 de abril de 2012. [Adobe Acrobat document. 14p.]. Available from: http://www.saude.mg.gov.br/images/documentos/ resolucao_3203.pdf

16. Pernambuco. Secretaria de Estado da Saúde [homepage on the
Internet]. Recife: a Secretaria; [cited 2018 Jul 22]. Norma Técnica SES/PE n ${ }^{\circ}$ 02/2013 e Portaria No 609, de 6 de junho de 2013. [Adobe Acrobat document. 7p.]. Available from: http://www.farmacia. pe.gov.br/sites/farmacia.saude.pe.gov.br/files/doenca_pulmonar_ obstrutiva_cronica___dpoc_pcdtent_rev02_1.pdf

17. Dormuth CR, Morrow RL, Carney G. Trends in health care utilization in British Columbia following public coverage for tiotropium. Value Health. 2011;14(4):600-6. https://doi.org/10.1016/j.jval.2010.11.018

18. Sociedade Brasileira de Pneumologia e Tisiologia; Associação de Medicina Intensiva Brasileira. Doença Pulmonar Obstrutiva Crônica: Exacerbação [monograph on the Internet]. Associação Médica Brasileira; 2012 [cited 2018 Oct 1]. Available from: https://diretrizes. amb.org.br/_BibliotecaAntiga/doenca_pulmonar_obstrutiva_cronica_ exacerbacao.pdf

19. Fernandes FLA, Cukier A, Camelier AA, Fritscher CC, Costa CHD, Pereira EDB, et al. Recommendations for the pharmacological treatment of COPD: questions and answers. J Bras Pneumol. 2017;43(4):290-301. https://doi.org/10.1590/s180637562017000000153

20. OPAS Brasil [homepage on the Internet]. Brasilia: Organização Pan-Americana da Saúde; [cited 2018 Jan 20]. Uso Racional de Medicamentos: fundamentação em condutas terapêuticas e nos macroprocessos da Assistência Farmacêutica. [Adobe Acrobat document, 3p.]. Available from: https://www.paho.org//bra/images/ stories/GCC/urm_capa.pdf?ua=1 